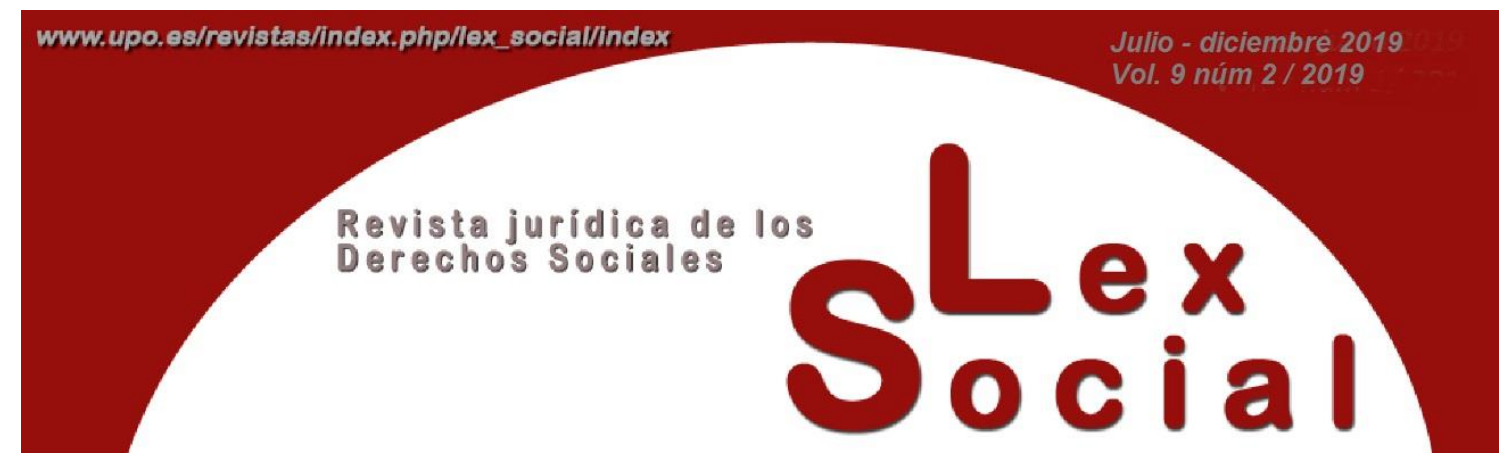

\title{
LOS PRONUNCIAMIENTOS DEL COMITÉ DESC SOBRE DERECHO A LA VIVIENDA RELATIVOS A ESPAÑA. RESPUESTAS JURISPRUDENCIALES Y LEGISLATIVAS
}

\section{CESCR DECISIONS ON THE RIGHT TO HOUSING IN SPAIN. DOMESTIC CASE LAW AND LEGISLATIVE RESPONSES}

\author{
Profesor JUAN CARLOS BENITO SÁNCHEZ \\ Investigador del F.R.S.-FNRS (FRESH) \\ Centre de philosophie du droit, UCLouvain (Bélgica)
}

Artículo recibido el 10 de mayo de 2019

Artículo aceptado 20 de mayo de 2019

\section{RESUMEN}

Este artículo examina los pronunciamientos del Comité de Derechos Económicos, Sociales y Culturales de Naciones Unidas (Comité DESC) sobre el derecho a la vivienda relativos a España y adoptados en el período 2017-2018, en particular en cuanto a los desalojos forzosos. Destaca, por su importancia y novedad, el dictamen del Comité DESC en el caso Ben Djazia et al. Seguidamente, se exponen y analizan las novedades jurisprudenciales y legislativas estatales en conexión con estos pronunciamientos, con el fin de evaluar si estas respuestas siguen la línea marcada por el Comité DESC e incorporan las garantías que rodean al derecho a una vivienda adecuada en Derecho internacional y europeo de los derechos humanos.

Palabras Clave: Comité DESC, derecho a la vivienda, España, jurisprudencia, legislación estatal, Derecho internacional y europeo de los derechos humanos 


\begin{abstract}
This article examines the decisions taken by the UN Committee on Economic, Social and Cultural Rights (CESCR) regarding the right to housing in Spain between 2017 and 2018, in particular concerning forced evictions. The Committee's views in the case of Ben Djazia et al. are especially noteworthy. Domestic case law and legislative developments are then presented and analysed, in order to evaluate whether these responses are aligned with the CESCR's interpretation and whether they incorporate the guarantees surrounding the right to adequate housing in international and European human rights law.
\end{abstract}

KEYwORDS: CESCR, right to housing, Spain, case law, national legislation, international and European human rights law

SUMARIO

\title{
1. Introducción
}

2. Los pronunciamientos del Comité DESC relativos a España en materia de vivienda (2017-2018)

2.1. Las Observaciones finales del Comité DESC sobre el sexto informe periódico de España (abril de 2018)

2.2. Las medidas provisionales solicitadas por el Comité DESC en el marco del mecanismo de comunicaciones individuales

2.3. El dictamen del Comité DESC en el caso Ben Djazia et al.: comentario y pistas de análisis

3. Novedades jurisprudenciales

3.1. Los efectos jurídicos de los dictámenes de órganos de supervisión de tratados: la STS 1263/2018

3.2. La obligatoriedad de realizar un juicio de proporcionalidad en ciertos procesos judiciales de desahucio: la STS 1797/2017

4. Novedades legislativas estatales

4.1. La Ley 5/2018, del "desahucio exprés"

4.2. El Real Decreto-ley 7/2019, de medidas urgentes en materia de vivienda y alquiler

5. Conclusión 


\section{Introducción}

El Comité de Derechos Económicos, Sociales y Culturales (Comité DESC) de Naciones Unidas es el órgano de expertos encargado de interpretar y evaluar el cumplimiento del Pacto Internacional de Derechos Económicos, Sociales y Culturales (PIDESC), en vigor desde 1976 y ratificado en 1977 por España ${ }^{1}$. Entre los derechos contenidos en el Pacto figura el derecho de toda persona a un nivel de vida adecuado para sí y su familia, "incluso alimentación, vestido y vivienda adecuados", y a una mejora continua de sus condiciones de existencia ${ }^{2}$. Este derecho a un nivel de vida adecuado, que tiene un sentido amplio, genera diversos derechos conexos que pueden ser entendidos de manera independiente: entre otros, el derecho a una vivienda adecuada ${ }^{3}$.

El PIDESC prevé un sistema de evaluación periódica de su implementación a través de informes presentados por los Estados parte conforme a un procedimiento inicialmente establecido por el Consejo Económico y Social de Naciones Unidas ${ }^{4}$. En la práctica, los Estados presentan sus informes cada cinco años. España presentó su sexto informe en octubre de 2017. El Comité DESC examina estos informes y, tras una serie de interacciones con el Estado a través de un diálogo constructivo, emite sus observaciones finales, que incluyen normalmente una serie de recomendaciones al Estado para lograr la plena efectividad de los derechos contenidos en el Pacto.

Además de este procedimiento de evaluación periódica, la ratificación por España del Protocolo Facultativo del Pacto Internacional de Derechos Económicos, Sociales y Culturales (PF-PIDESC) en 2010 supuso el reconocimiento de la competencia del Comité DESC para recibir y examinar comunicaciones presentadas por personas o grupos de personas bajo jurisdicción española que aleguen ser víctimas de una violación por parte de España de alguno de los derechos enunciados en el Pacto ${ }^{5}$. El Protocolo Facultativo, en vigor desde el 5 de mayo de 2013, crea, por tanto, un sistema de reclamaciones individuales en caso de agotamiento de los recursos internos o en caso de que la tramitación de estos recursos se prolongue injustificadamente. Una vez examinada la comunicación presentada por los autores, el Comité emite un dictamen, que suele ir acompañado de recomendaciones al Estado. El Estado dará entonces "la debida consideración al dictamen del Comité, así como a sus recomendaciones, si las hubiere"ø.

\footnotetext{
1 Asamblea General, Pacto Internacional de Derechos Económicos, Sociales y Culturales, Pacto Internacional de Derechos Civiles y Políticos y Protocolo Facultativo del Pacto Internacional de Derechos Civiles y Políticos, A/RES/2200 (XXI) (16 de diciembre de 1966).

${ }^{2}$ Asamblea General, Pacto Internacional de Derechos Económicos, Sociales y Culturales, art. 11, párr. 1.

${ }^{3}$ Véase Comité de Derechos Económicos, Sociales y Culturales, Observación general núm. 4: El derecho a una vivienda adecuada (párrafo 1 del artículo 11 del Pacto), E/1992/23 (1 de enero de 1992).

${ }^{4}$ Asamblea General, Pacto Internacional de Derechos Económicos, Sociales y Culturales, arts. 16 y ss.

5 Asamblea General, Protocolo Facultativo del Pacto Internacional de Derechos Económicos, Sociales y Culturales, A/RES/63/117 (10 de diciembre de 2008).

${ }^{6}$ Asamblea General, Protocolo Facultativo del Pacto Internacional de Derechos Económicos, Sociales y Culturales, art. 9, párr. 1. 
El Comité DESC publicó su primer dictamen relativo al derecho a la vivienda el 13 de octubre de 2015, en el caso I.D.G. c. España ${ }^{7}$. Se trataba de un caso de impago de las cuotas debidas a una entidad bancaria con motivo de un contrato de préstamo con garantía hipotecaria, que llevó a la entidad a instar un procedimiento de ejecución hipotecaria contra la autora de la comunicación. Ante la dificultad para localizarla y tras algunos intentos fallidos de notificación personal, se procedió a la notificación por edicto. Como consecuencia, la autora solo tomó conocimiento del proceso una vez fue ordenada la subasta de su vivienda. El juzgado de primera instancia desestimó su recurso de reposición contra la diligencia ordenando la subasta y, posteriormente, el Tribunal Constitucional inadmitió su recurso de amparo. La autora presentó una comunicación ante el Comité DESC en el marco del Protocolo Facultativo, alegando una vulneración de su derecho a una vivienda adecuada.

La autora subrayó ante el Comité la situación de grave crisis habitacional en España y alegó una vulneración de su derecho a la tutela judicial efectiva en conexión con su derecho a la vivienda, puesto que la notificación del proceso de ejecución hipotecaria se realizó sin observar todas las garantías debidas y dado que la falta de acceso a un recurso efectivo le impidió denunciar el carácter abusivo de ciertas cláusulas de su contrato de préstamo. El Comité DESC constató en su dictamen una vulneración del derecho a una vivienda adecuada, al considerar que el juzgado no tomó todas las medidas razonables para notificar adecuadamente a la autora de la demanda de ejecución hipotecaria. ${ }^{8}$

No cabe duda de que la relevancia política y mediática en España de los pronunciamientos del Comité DESC se ha multiplicado a raíz de este primer dictamen. Los dos dictámenes del Comité en materia de vivienda adoptados hasta la fecha -I.D.G. c. España y Ben Djazia et al.-, así como sus observaciones finales y sus solicitudes de medidas provisionales, han sido ampliamente difundidos en medios de comunicación y movilizados por movimientos sociales ${ }^{9}$. Cabe preguntarse, sin embargo, si la

\footnotetext{
${ }^{7}$ Comité de Derechos Económicos, Sociales y Culturales, Comunicación núm. 2/2014, E/C.12/55/D/2/2014 (13 de octubre de 2015).

${ }^{8}$ Véase, para un análisis más detenido, Juan Carlos Benito Sánchez, 'The UN Committee on Economic, Social and Cultural Rights' Decision in I.D.G. v. Spain: The Right to Housing and Mortgage Foreclosures', European Journal of Human Rights / Journal européen des droits de l'homme 2016, no. 3 (2016): 320339.

${ }^{9}$ Véase, por ejemplo, Galaup, Laura, "La ONU dictamina que España violó los derechos de una familia desahuciada que acabó durmiendo en un coche", eldiario.es, 5 de julio de 2017, https://www.eldiario.es/sociedad/ONU-dictamina-Espana-desahuciada-durmiendo_0_661784476.html; "España violó el derecho a la vivienda de una familia con hijos menores en un desahucio", Público, 5 de julio de 2017, https://www.publico.es/sociedad/vivienda-espana-violo-derecho-vivienda-familia-hijosmenores-desahucio.html; "El Comité de Derechos Económicos, Sociales y Culturales de la ONU reconoce el derecho de los inquilinos a una vivienda adecuada", Red-DESC, 7 de julio de 2017, https://www.escrnet.org/es/noticias/2017/comite-derechos-economicos-sociales-y-culturales-onu-reconoce-derecho-

inquilinos-una; "Naciones Unidas condena a España por no garantizar vivienda alternativa a una familia desahuciada", Amnistía Internacional, 5 de julio de 2017, https://www.es.amnesty.org/en-queestamos/noticias/noticia/articulo/naciones-unidas-condena-a-espana-por-no-garantizar-viviendaalternativa-a-una-familia-desahuciada/.
} 
interpretación realizada por el Comité DESC del derecho a una vivienda adecuada ha permeado en nuestra jurisprudencia y nuestra legislación.

En otras palabras, ¿podemos constatar un cambio de tendencia hacia la toma en consideración de los pronunciamientos del Comité DESC en materia de vivienda a nivel jurisprudencial y legislativo? Este artículo pretende dar una respuesta general a esta pregunta a través de un resumen analítico de los pronunciamientos del Comité DESC relativos a España en materia de vivienda entre 2017 y 2018 (2), así como de las novedades jurisprudenciales (3) y legislativas a nivel estatal (4) surgidas a este respecto. El estudio se centra en el dictamen del Comité DESC en el caso Ben Djazia et al. y en los desalojos forzosos, para poder delimitar y profundizar mejor en nuestro análisis.

\section{Los pronunciamientos del Comité DESC relativos a España en materia de vivienda (2017-2018)}

Los pronunciamientos del Comité DESC pueden recaer en el marco del examen periódico a los Estados parte en el PIDESC (2.1) o bien en el marco del mecanismo de comunicaciones individuales introducido por el Protocolo Facultativo. En este último caso, los pronunciamientos pueden estar incluidos en una solicitud de medidas provisionales mientras el Comité examina una comunicación (2.2) o en el dictamen final que el Comité emite una vez concluido su examen (2.3).

\subsection{Las Observaciones finales del Comité DESC sobre el sexto informe periódico de España (abril de 2018)}

Conforme al artículo 16 del PIDESC, los Estados parte se comprometen a presentar informes periódicos ante el Comité DESC relativos a las medidas adoptadas y al progreso realizado en la protección de los derechos contenidos en el Pacto. En el caso de España, opera el procedimiento conocido como "procedimiento simplificado de presentación de informes", que se articula a través de un cuestionario previo transmitido por el Comité, con una serie de preguntas agrupadas en distintas temáticas ${ }^{10}$. Una vez recibido el cuestionario, el Estado presenta un informe dando respuesta a esas cuestiones. El Comité y el Estado entablan, por medio de este procedimiento, un diálogo constructivo, en el que los miembros del Comité pueden recibir respuestas de manera oral por parte de una delegación estatal multisectorial. En este mismo procedimiento intervienen también organizaciones de la sociedad civil.

En sus Observaciones finales sobre el sexto informe periódico de España, publicadas el 25 de abril de $2018^{11}$, el Comité DESC lamenta con carácter general que los derechos

\footnotetext{
${ }^{10}$ Véase Naciones Unidas, Procedimiento simplificado de presentación de informes, HRI/MC/2014/4 (14 de abril de 2014).

${ }^{11}$ Comité de Derechos Económicos, Sociales y Culturales, Observaciones finales sobre el sexto informe periódico de España, E/C.12/ESP/CO/6 (25 de abril de 2018). 
económicos, sociales y culturales en España sigan siendo considerados como meros principios rectores de la política social y económica y que, en términos generales, estos puedan ser únicamente invocados tras su posterior desarrollo legislativo. Como elemento central, el Comité critica que España no disponga de un mecanismo adecuado para aplicar los dictámenes y recomendaciones del Comité ${ }^{12}$. Asimismo, valora negativamente la persistencia de disparidades entre diferentes comunidades autónomas, e insta a España a mejorar sus sistemas de coordinación entre el gobierno central y las comunidades autónomas encargadas de prestar servicios públicos de bienestar social ${ }^{13}$.

Específicamente en materia de vivienda, preocupan al Comité el número insuficiente de viviendas sociales, la creciente falta de asequibilidad de la vivienda (particularmente en el mercado privado) debido a los precios excesivos y la falta de protección adecuada de la seguridad de la tenencia, así como el elevado número de hogares sin vivienda adecuada y de personas $\sin$ hogar ${ }^{14}$.

Analiza también el Comité la cuestión de los desalojos, subrayando "la falta de un marco legislativo adecuado que determine las debidas garantías legales y procesales para las personas afectadas" 15 . Conforme a ello, recomienda que España:

Adopte un marco legislativo que establezca requisitos y procedimientos adecuados para llevar a cabo desahucios o desalojos forzados, que entre otros incorpore los principios de razonabilidad y proporcionalidad, así como las debidas garantías legales y procesales para las personas afectadas, asegurando que las personas afectadas tengan acceso a una compensación o la opción de una vivienda alternativa adecuada, sean informadas con un plazo suficiente y razonable de notificación sobre las decisiones que ordenen los desahucios y tengan acceso a un recurso judicial efectivo. El Comité recomienda al Estado parte que adopte un protocolo de actuación en casos de desahucios que asegure una coordinación adecuada entre los tribunales y los servicios sociales locales, así como entre los servicios sociales mismos, a fin de brindar una protección adecuada a las personas que puedan quedarse sin hogar como resultado del desahucio ${ }^{16}$.

En resumen, destaca el mandato al Estado de establecer procedimientos adecuados de desalojo que permitan evaluar la proporcionalidad del lanzamiento, prevean una alternativa habitacional adecuada y garanticen el acceso a un recurso judicial efectivo. Además, se recomienda la puesta en marcha de un protocolo de coordinación entre los

\footnotetext{
12 Observaciones finales sobre el sexto informe periódico de España, párr. 5.

${ }^{13}$ Observaciones finales sobre el sexto informe periódico de España, párr. 12.

${ }^{14}$ Observaciones finales sobre el sexto informe periódico de España, párr. 35.

${ }^{15}$ Observaciones finales sobre el sexto informe periódico de España, párr. 37.

${ }^{16}$ Observaciones finales sobre el sexto informe periódico de España, párr. 38.
} 
tribunales y las administraciones públicas encargadas de gestionar recursos contra el sinhogarismo.

\subsection{Las medidas provisionales solicitadas por el Comité DESC en el marco del mecanismo de comunicaciones individuales}

Dentro del mecanismo de examen de comunicaciones individuales habilitado por el Protocolo Facultativo del PIDESC, el Comité puede dirigir al Estado una solicitud de medidas provisionales en cualquier momento tras haber recibido una comunicación y antes de pronunciarse sobre el fondo. Estas medidas serán las "necesarias en circunstancias excepcionales a fin de evitar posibles daños irreparables a la víctima o las víctimas de la supuesta violación"17. Esta facultad no implica juicio alguno sobre la admisibilidad o sobre el fondo de la comunicación.

En los últimos meses, el Comité DESC ha utilizado esta potestad para solicitar la suspensión de un gran número de lanzamientos en procesos de desahucio en curso en los que una alternativa habitacional adecuada no estaba garantizada. La efectividad práctica de estas solicitudes de medidas provisionales es, sin embargo, variable: de acuerdo con los reportes de medios de comunicación y movimientos sociales, estas solicitudes le llegan frecuentemente al juez a través del abogado de los demandados, en vez de trasmitírselas el Estado por una vía de comunicación oficial. Además, estas solicitudes no son siempre atendidas: en varios casos, el juez ha ordenado que se proceda al lanzamiento a pesar de existir una solicitud de medidas provisionales del Comité DESC, al considerar que estas solicitudes tienen un valor interpretativo pero no vinculante ${ }^{18}$.

En este tipo de solicitudes, dirigidas a la Misión Permanente de España ante la Oficina de las Naciones Unidas en Ginebra, el Comité recuerda el contenido de sus Observaciones Generales núms. 4 y 7, que estipulan, entre otros, que los desalojos no pueden tener como consecuencia que personas se queden sin vivienda o que queden expuestas a violaciones de otros derechos humanos y que, cuando los afectados no dispongan de recursos suficientes, el Estado debe adoptar todas las medidas necesarias hasta el máximo de sus recursos disponibles para que se les proporcione otra vivienda ${ }^{19}$. Seguidamente, el Comité

\footnotetext{
${ }^{17}$ Asamblea General, Protocolo Facultativo del Pacto Internacional de Derechos Económicos, Sociales y Culturales, art. 5, párr. 1.

${ }^{18}$ Véase Galaup, Laura, "España desoye un dictamen de la ONU que le insta a evitar desahucios de familias vulnerables", eldiario.es, 21 de noviembre de 2017, https:/www.eldiario.es/sociedad/desahuciosONU_0_710429404.html; Sanz Paratcha, Diego, "La lluvia fina de las órdenes de la ONU contra los desahucios en España", El Salto, 18 de julio de 2018, https://www.elsaltodiario.com/vivienda/desahuciosmedidas-cautelares-onu-españa; Núñez-Villaveirán, Luis, "Una familia podría ser desalojada pese a un escrito contrario de Naciones Unidas", El Mundo, 29 de marzo de 2018, http://www.elmundo.es/madrid/2018/03/29/5abbc1a646163f142e8b4664.html; "La ONU ordena la suspensión cautelar del desahucio de una familia con dos niñas en Madrid”, RTVE, 28 de marzo de 2018, http://www.rtve.es/noticias/20180328/onu-ordena-suspension-cautelar-del-desahucio-familia-dos-ninasmadrid/1704640.shtml.

${ }^{19}$ Véase Comité de Derechos Económicos, Sociales y Culturales, Observación general núm. 4: El derecho a una vivienda adecuada (párrafo 1 del artículo 11 del Pacto); Comité de Derechos Económicos, Sociales ISSN: 2174-6419 Lex Social, vol. 9, núm. 2 (2019)
} 
solicita al Estado que tome medidas para evitar posibles daños irreparables a los autores de la comunicación mientras su caso es examinado por el Comité, incluyendo la suspensión del desahucio de la vivienda que ocupan o, alternativamente, la garantía de una vivienda alternativa adecuada a sus necesidades, todo ello en el marco de una consulta genuina y efectiva con los autores.

Cabe destacar, por tanto, la falta de un cauce procesal específico por el que estas solicitudes de medidas provisionales puedan ser transmitidas de manera directa al juez o tribunal responsable, así como una provisión que garantice la obligatoriedad de aplicar estas medidas como parte de las garantías procedimentales reconocidas en el ordenamiento jurídico español.

\subsection{El dictamen del Comité DESC en el caso Ben Djazia et al.: comentario y pistas de análisis}

El 20 de junio de 2017, el Comité DESC emitió su segundo dictamen relativo al derecho a la vivienda en el caso Ben Djazia et al. (también conocido como M.B.D. c. España) ${ }^{20}$. Esta comunicación aborda precisamente la cuestión de los procesos de desahucio y los lanzamientos sin alternativa habitacional adecuada, y la responsabilidad del Estado en este contexto bajo el Derecho internacional de los derechos humanos. La relevancia de este dictamen nos lleva a detenernos sobre los hechos que lo ocasionaron, así como el razonamiento jurídico del Comité y las recomendaciones formuladas al Estado español.

El dictamen examina el caso de Mohamed Ben Djazia, Naouel Bellili y sus dos hijos menores de edad, de uno y tres años en aquel momento. Los autores vivían con sus hijos en una habitación alquilada en un piso en Madrid. Pese a haber presentado solicitudes de vivienda social de manera repetida durante doce años, ninguna de estas fue atendida. Una vez agotado el subsidio por desempleo que recibía Ben Djazia, los autores se vieron ante la imposibilidad de hacer frente al pago de su alquiler durante varios meses. El plazo contractual terminó, habiendo manifestado la arrendadora con anterioridad su voluntad de no prorrogar el contrato. Sin embargo, los autores se negaron a abandonar la habitación, ya que no disponían de alojamiento alternativo. La arrendadora interpuso una demanda de juicio verbal de desahucio. Ben Djazia solicitó en ese momento asistencia jurídica gratuita, que fue denegada por considerarse insostenible su pretensión ${ }^{21}$.

El juzgado de primera instancia declaró concluido el contrato de arrendamiento por expiración del plazo contractual y ordenó el desalojo de los autores. El juzgado tomó nota de su situación económica y familiar, dando traslado a los organismos correspondientes

\footnotetext{
y Culturales, Observación general núm. 7: El derecho a una vivienda adecuada (párrafo 1 del artículo 11 del Pacto): los desalojos forzosos, E/1998/22 (20 de mayo de 1997).

20 Comité de Derechos Económicos, Sociales y Culturales, Comunicación núm. 5/2015, E/C.12/61/D/5/2015 (21 de julio de 2017).

${ }^{21}$ Comité de Derechos Económicos, Sociales y Culturales, Comunicación núm. 5/2015, párr. 2.1 y ss. ISSN: 2174-6419 Lex Social, vol. 9, núm. 2 (2019)
} 
en materia de servicios sociales, tanto autonómicos como municipales. Los autores se opusieron al desalojo, alegando que ello equivaldría a una vulneración de su derecho a una vivienda digna y adecuada. Tras ser rechazada su oposición, estos interpusieron un recurso de reposición, que fue desestimado. Seguidamente, presentaron un recurso de amparo ante el Tribunal Constitucional, sin que este decretara medidas cautelares suspendiendo el lanzamiento. Los autores fueron finalmente desalojados. Durmieron en un albergue municipal durante diez días, plazo máximo tras el cual debían abandonarlo. Ante la ausencia de alternativa habitacional, se vieron abocados a dormir con sus hijos de corta edad en el automóvil familiar durante cuatro noches, hasta que un conocido les ofreció un alojamiento temporal.

Los autores alegaron ante el Comité DESC una vulneración de su derecho a la vivienda, indicando que el proceso judicial de desahucio no observó las debidas garantías, puesto que la legislación española no permite a los tribunales evaluar las consecuencias de un desalojo forzoso ni las circunstancias particulares de cada caso. Recuerdan que la legislación española solamente prevé que en los procesos judiciales de desahucio los demandados se opongan alegando el pago total o parcial del alquiler o cuestionando otros extremos como la legitimación activa o el plazo contractual, pero estos no pueden oponerse al desalojo sobre la base de que ello conllevaría una vulneración de su derecho a la vivienda o los expondría a otras violaciones de derechos humanos ${ }^{22}$. En caso de querer interponer un recurso de apelación, extraordinario por infracción procesal o de casación, los demandados deben manifestar por escrito que han abonado las rentas vencidas y las que con arreglo al contrato deban pagar adelantadas ${ }^{23}$. Finalmente, aunque interpongan un recurso de amparo, que no tiene por sí mismo efectos suspensivos, el Tribunal Constitucional raramente adopta medidas cautelares suspendiendo el lanzamiento ${ }^{24}$.

Cabe destacar la intervención de la Relatora Especial de Naciones Unidas sobre una vivienda adecuada como elemento integrante del derecho a un nivel de vida adecuado y sobre el derecho de no discriminación a este respecto ${ }^{25}$. Sin entrar a valorar las denuncias de los autores en el caso específico, la relatora subraya el hecho de que los autores no tuvieron recursos efectivos frente a los tribunales domésticos que pudieran haber impedido su situación de sinhogarismo y critica que la legislación aplicable permita que un contrato de arrendamiento termine por la simple expiración del plazo contractual, sin

\footnotetext{
${ }^{22}$ Véase Ley 1/2000, de 7 de enero, de Enjuiciamiento Civil, Boletín Oficial del Estado, 8 de enero de 2001, núm. 7, p. 575 , arts. 441.1 bis y 444.1 bis.

${ }^{23}$ Véase Ley 1/2000, de 7 de enero, de Enjuiciamiento Civil, art. 449.1.

${ }^{24}$ Véase Ley Orgánica 2/1979, de 3 de octubre, del Tribunal Constitucional, Boletín Oficial del Estado, 25 de octubre de 1979, núm. 239, p. 23186, art. 56.

${ }^{25}$ Relatora Especial de Naciones Unidas sobre una vivienda adecuada como elemento integrante del derecho a un nivel de vida adecuado y sobre el derecho de no discriminación a este respecto, Sra. Leilani Farha, Comunicación 5/2015: MDB [sic] et al. c. España, 31 de enero de 2017. 
que existan causas tasadas en ausencia de las cuales el contrato deba ser obligatoriamente renovado ${ }^{26}$.

En su dictamen, el Comité DESC recuerda que el derecho humano a una vivienda adecuada es un derecho fundamental que debe garantizarse a todos, sean cuales fueren sus ingresos o su acceso a recursos económicos. En el marco del PIDESC, los Estados deben tomar todas las medidas necesarias para lograr la plena realización de este derecho, hasta el máximo de sus recursos disponibles. El derecho a la vivienda implica que todos deben gozar de un grado de seguridad de tenencia tal que les garantice una protección legal contra los desalojos, y esta garantía también se aplica a los arrendatarios de vivienda, sea el titular de esta una administración pública o un propietario privado ${ }^{27}$.

El Comité evoca asimismo la prohibición de los desalojos forzosos, que son a priori incompatibles con los requisitos del Pacto y solo pueden justificarse en las circunstancias más excepcionales y de conformidad con el Derecho internacional de los derechos humanos. La expresión "desalojo forzoso" cobra aquí un sentido técnico-jurídico y se refiere precisamente a los desalojos que no cumplen con los requisitos del Pacto y del Derecho internacional aplicable. Este término no se limita, por tanto, a los desalojos a gran escala de comunidades enteras y se aplica también a los supuestos de ocupación sin título ${ }^{28}$.

Las autoridades competentes deben garantizar la observancia de los principios de razonabilidad y proporcionalidad, así como el respeto de las garantías procesales, que deben incluir una auténtica oportunidad de consulta genuina y efectiva con los afectados. Puesto que no existe derecho sin recurso efectivo, el Comité apunta que los Estados deben garantizar que las personas cuyo derecho a la vivienda pudiera resultar afectado disponen de un recurso judicial efectivo y apropiado.

Por tanto, para poder proceder a un desahucio por impago de alquiler sin que este sea considerado un desalojo forzoso, deben concurrir los siguientes requisitos: la medida debe estar prevista por ley, debe realizarse como último recurso, las personas afectadas deben tener acceso a un recurso judicial efectivo en el que se dirima si la medida está debidamente justificada, debe existir una consulta genuina y efectiva con los afectados, no deben existir medios alternativos o medidas menos gravosas y las personas afectadas no deben quedar en una situación que constituya una violación de derechos humanos o que los exponga a ello ${ }^{29}$.

\footnotetext{
${ }^{26}$ Relatora Especial de Naciones Unidas sobre una vivienda adecuada como elemento integrante del derecho a un nivel de vida adecuado y sobre el derecho de no discriminación a este respecto, Sra. Leilani Farha, Comunicación 5/2015: MDB [sic] et al. c. España, párr. 26.

${ }^{27}$ Comité de Derechos Económicos, Sociales y Culturales, Comunicación núm. 5/2015, párr. 13.1 y ss.

${ }^{28}$ Véase Relatora Especial de Naciones Unidas sobre una vivienda adecuada como elemento integrante del derecho a un nivel de vida adecuado y sobre el derecho de no discriminación a este respecto, Sra. Leilani Farha, Comunicación 5/2015: MDB [sic] et al. c. España, párr. 27.

${ }^{29}$ Comité de Derechos Económicos, Sociales y Culturales, Comunicación núm. 5/2015, párr. 15.1. ISSN: $2174-6419$ Lex Social, vol. 9, núm. 2 (2019)
} 
Procede citar completo, por su relevancia, el siguiente fragmento:

"En particular, los desalojos no deberían dar lugar a que los afectados queden sin vivienda. Por tanto, si no disponen de recursos para una vivienda alternativa, los Estados partes deberán adoptar todas las medidas necesarias para que en lo posible se les proporcione otra vivienda, reasentamiento o acceso a tierras productivas, según proceda. Los Estados partes deben prestar especial atención a los casos en que los desalojos afecten a mujeres, niños, personas mayores, personas con discapacidad, así como a otros individuos o grupos que sufran discriminación sistémica o estén en una situación de vulnerabilidad. El Estado parte tiene el deber de adoptar medidas razonables para proveer vivienda alternativa a las personas que puedan quedar sin techo como consecuencia de un desalojo, independientemente de si tal desalojo ocurre a instancia de las autoridades del Estado parte o de particulares, como el arrendador" ${ }^{\prime 3}$.

En el caso de Ben Djazia, el Comité toma nota de que el desalojo tuvo lugar sin evaluar las posibles consecuencias de esta medida sobre los autores y en particular sobre sus hijos menores. Considera, en consecuencia, que el hecho de que el desalojo de los autores se llevara a cabo sin que existiera una confirmación de la disponibilidad de vivienda alternativa constituyó una violación del derecho de los autores a una vivienda adecuada, dado que el Estado no demostró haber realizado todos los esfuerzos posibles utilizando todos los recursos a su disposición con este fin ${ }^{31}$.

Una vez constatada la violación del Pacto, el Comité formula una serie de recomendaciones al Estado. Respecto de los autores, se les debe una reparación efectiva: ello implica, en caso de que aún no cuenten con una vivienda adecuada, evaluar su situación y otorgarles una vivienda pública o tomar otras medidas que les permitan vivir en una vivienda adecuada, más una compensación económica ${ }^{32}$. Con carácter general, el Comité considera que España debe, entre otros:

"Adoptar medidas legislativas y/o administrativas pertinentes para garantizar que, en los procesos judiciales de desalojos de inquilinos, los demandados puedan oponerse o presentar un recurso con el fin de que el juez considere las consecuencias del desalojo y la compatibilidad de esta medida con el Pacto.

Adoptar las medidas necesarias para superar los problemas de falta de coordinación entre las decisiones judiciales y las acciones de los servicios

\footnotetext{
${ }^{30}$ Comunicación núm. 5/2015, párr. 15.2.

${ }^{31}$ Comunicación núm. 5/2015, párr. 18.

${ }^{32}$ Comunicación núm. 5/2015, párr. 20. 
sociales que pueden conducir a que una persona desalojada pueda quedar sin vivienda adecuada.

Adoptar las medidas necesarias para asegurarse de que los desalojos que afecten a personas sin recursos para procurarse una vivienda alternativa, sólo se ejecuten después de que haya habido una consulta genuina y efectiva con estas personas y de que el Estado parte haya realizado todos los pasos indispensables, hasta el máximo de sus recursos disponibles, para que las personas desalojadas tengan una vivienda alternativa, en especial en aquellos casos que involucran a familias, personas mayores, niños $y / u$ otras personas en situación de vulnerabilidad"33.

Junto al claro valor interpretativo de este dictamen para determinar el alcance de las garantías que rodean al derecho a una vivienda adecuada en Derecho internacional de los derechos humanos, pueden subrayarse por tanto los siguientes elementos: la necesidad de observar los principios de razonabilidad y proporcionalidad antes de ordenar un lanzamiento, el necesario acceso de los afectados a un recurso judicial efectivo y apropiado y la necesaria oportunidad de una consulta genuina y efectiva con ellos.

\section{Novedades jurisprudenciales}

Una vez presentado este resumen analítico de los pronunciamientos del Comité DESC en materia de vivienda, pasamos a considerar su recepción en la jurisprudencia doméstica y en la legislación estatal. Partiendo de la ausencia de jurisprudencia que mencione de manera explícita el dictamen en el caso Ben Djazia et al. o los otros pronunciamientos del Comité citados, nos centramos aquí en dos sentencias del Tribunal Supremo (TS) que abordan elementos importantes en este sentido: en una se discuten los efectos jurídicos de los dictámenes de órganos de supervisión de tratados (3.1), mientras que en la otra se analiza la obligatoriedad de realizar un juicio de proporcionalidad en ciertos procesos judiciales de desahucio (3.2).

\subsection{Los efectos jurídicos de los dictámenes de órganos de supervisión de tratados: la STS 1263/2018}

Para analizar el valor jurídico de la obligación de reparar a los autores contenida en pronunciamientos de órganos de expertos creados en virtud de tratados de derechos humanos, que en Ben Djazia et al. se articula como una indemnización pecuniaria más una obligación de evaluar la situación de los autores y otorgarles una vivienda pública o tomar otras medidas que les permitan vivir en una vivienda adecuada, podemos referirnos a la Sentencia del Tribunal Supremo 1263/2018, de 17 de julio de 2018 ${ }^{34}$. Como

\footnotetext{
${ }^{33}$ Comunicación núm. 5/2015, párr. 21.

${ }^{34}$ Tribunal Supremo (Sala de lo Contencioso-Administrativo, Sección 4ª), Sentencia núm. 1263/2018, 17 de julio de 2018 . 
apuntaremos, aunque esta sentencia se enmarca en un proceso de reclamación de responsabilidad patrimonial del Estado, el Tribunal Supremo realiza una serie de consideraciones jurídicas que pueden aplicarse también a las recomendaciones de alcance general contenidas en dictámenes de órganos como el Comité DESC.

La sentencia del Tribunal Supremo examina la efectividad jurídica de un dictamen del Comité CEDAW, emitido dentro del sistema de reclamaciones individuales propio a esa convención. El Comité CEDAW es el órgano de expertos vinculado a la Convención sobre la eliminación de todas las formas de discriminación contra la mujer, cuyo Protocolo Facultativo prevé un sistema de comunicaciones individuales similar al contenido en el PIDESC ${ }^{35}$.

Se trataba en este caso de una comunicación presentada por una mujer cuya hija fue asesinada a manos de su expareja debido a una modificación en el régimen de visitas acordado por el juez, que pasó de ser con vigilancia a no vigilado, sin las necesarias salvaguardas y sin tener en cuenta los patrones de violencia contra la mujer que caracterizaron a las relaciones familiares durante años ${ }^{36}$. El Comité CEDAW constató la vulneración de varios de los derechos contenidos en la Convención, ordenando al Estado que otorgara a la autora una reparación adecuada y una indemnización integral y proporcional a la gravedad de la conculcación de sus derechos, y que llevara a cabo "una investigación exhaustiva e imparcial con miras a determinar la existencia de fallos en las estructuras y prácticas estatales que hayan ocasionado una falta de protección de la autora y su hija"37.

La sentencia del Tribunal Supremo que consideramos se centra en evaluar si las recomendaciones formuladas por el Comité CEDAW en su dictamen son vinculantes para España. Se plantea cuál debe ser el cauce adecuado para solicitar al Estado el cumplimiento de los dictámenes del Comité CEDAW y si la inexistencia de un procedimiento en Derecho interno que prevea la eficacia ejecutiva de este tipo de resoluciones implica que su cumplimiento se puede exigir de manera autónoma.

Cabe recalcar, en todo caso, que no estamos aquí ante una sentencia que analice como objeto principal la efectividad jurídica de aquellos elementos del dictamen del Comité CEDAW que recaen con carácter general sobre el incumplimiento de los derechos contenidos en la Convención, sino más bien sobre la efectividad jurídica de la

\footnotetext{
${ }^{35}$ Véase Asamblea General, Convención sobre la eliminación de todas las formas de discriminación contra la mujer, A/RES/34/180 (18 de diciembre de 1979); Asamblea General, Protocolo Facultativo de la Convención sobre la eliminación de todas las formas de discriminación contra la mujer, A/RES/54/4 (15 de octubre de 1999).

${ }^{36}$ Véase Comité para la Eliminación de la Discriminación contra la Mujer, Comunicación núm. 47/2012, CEDAW/C/58/D/47/2012 (15 de agosto de 2014); Casla, Koldo, "Supreme Court of Spain: UN Treaty Body individual decisions are legally binding”, EJIL: Talk!, 1 de agosto de 2018, https://www.ejiltalk.org/supreme-court-of-spain-un-treaty-body-individual-decisions-are-legally-binding/. 37 Comité para la Eliminación de la Discriminación contra la Mujer, Comunicación núm. 47/2012, párr. 11.a).
} 
recomendación específica de reparar a la autora. Así, el Tribunal Supremo entiende que concurre interés casacional objetivo en tanto en cuanto "se contienen en tales dictámenes recomendaciones dirigidas a nuestras autoridades a fin de que reparen los daños derivados del incumplimiento constatado de los derechos previstos en la Convención" ${ }^{38}$.

La sentencia del Tribunal Supremo casa y anula la anterior sentencia emitida por la Audiencia Nacional en este proceso, que descartó la existencia de un funcionamiento anormal de la Administración de Justicia y afirmó que no se apreciaba la existencia de los elementos necesarios para declarar un supuesto de responsabilidad patrimonial del Estado. El Tribunal confirma primero la inexistencia de un cauce procesal específico y autónomo para instar el cumplimiento de los dictámenes del Comité CEDAW. Por ello, es necesario evaluar si el dictamen puede por sí mismo servir de base para formular una reclamación de responsabilidad patrimonial, a lo que el TS da una respuesta positiva. Su argumentación se articula en varios pasos y merece ser reproducida aquí por su relevancia de cara a los efectos jurídicos de los dictámenes de órganos de vigilancia de tratados.

En primer lugar, considera que la Convención no añade una instancia superior supranacional en sentido estricto de revisión o control directo de las decisiones judiciales o administrativas internas, ni impone a los estados unas medidas procesales concretas para asegurar la reparación de las violaciones de derechos que se puedan constatar.

En segundo lugar, confirma que los dictámenes del Comité CEDAW son vinculantes y obligatorios para el Estado. Este análisis, que parece extensible en su integridad a los dictámenes del Comité DESC, es especialmente relevante para nuestro estudio. El TS recuerda que el dictamen "emana de un órgano creado en el ámbito de una normativa internacional que, por expresa previsión del artículo 96 de la Constitución Española, forma parte de nuestro ordenamiento jurídico interno" y añade que "las normas relativas a los derechos fundamentales se interpretarán de conformidad con la Declaración Universal de Derechos Humanos y los tratados y acuerdos internacionales sobre las mismas materias ratificados por España" ${ }^{39}$.

Dado que el dictamen se ha emitido en el seno de un procedimiento expresamente regulado, con garantías y con plena participación de España y con base en los principios de legalidad y jerarquía normativa, se afirma, crucialmente, que "las obligaciones internacionales relativas a la ejecución de las decisiones de los órganos internacionales de control cuya competencia ha aceptado España forman parte de nuestro ordenamiento interno" ${ }^{40}$.

Por todo lo anterior, considera el Tribunal que:

\footnotetext{
${ }^{38}$ Tribunal Supremo (Sala de lo Contencioso-Administrativo, Sección 4 ${ }^{\text {a }}$, Sentencia núm. 1263/2018, p. 7.

${ }^{39}$ Sentencia núm. 1263/2018, p. 24.

${ }^{40}$ Sentencia núm. 1263/2018, p. 25.

ISSN: 2174-6419

Lex Social, vol. 9, núm. 2 (2019)
} 
"Ante la inexistencia de un procedimiento especifico de ejecución de los dictámenes del Comité de la CEDAW, que es en sí mismo un incumplimiento de un mandato legal y constitucional por parte España [sic], el que la recurrente pueda disponer de un cauce adecuado y eficaz para hacer valer el reconocimiento de la vulneración de sus derechos fundamentales ante los órganos judiciales españoles atañe directamente al respeto y observancia por los poderes públicos españoles de los derechos fundamentales de la recurrente" ${ }^{\text {41. }}$.

Concluye, por tanto, que existe una obligación de reparar la vulneración haciendo efectiva la condena a la reparación del daño evaluable económicamente ${ }^{42}$.

Existe, a pesar de ello, una cierta ambigüedad con respecto al alcance de esta doctrina. Si bien la formulación de la cuestión a la que el Tribunal Supremo otorga interés casacional se restringe a supuestos de reparación e indemnización a los autores, la argumentación jurídica desarrollada parece ser extensible a las recomendaciones de alcance general contenidas en estos dictámenes, a la luz de la articulación del sistema de fuentes y de las obligaciones internacionales que vinculan a España realizada por el Tribunal. Sería deseable que futura jurisprudencia del TS clarificase cuál es el valor jurídico que otorga a las recomendaciones de carácter general contenidas en los dictámenes de este tipo de órganos, y si este valor difiere en algún sentido de las recomendaciones de carácter específico relativas a la reparación del daño sufrido por los autores.

\subsection{La obligatoriedad de realizar un juicio de proporcionalidad en ciertos procesos judiciales de desahucio: la STS 1797/2017}

La obligatoriedad de realizar un juicio de proporcionalidad en los procesos judiciales de desahucio, reiterada por el Comité DESC, parece haber encontrado cierta recepción jurisprudencial en la Sentencia del Tribunal Supremo 1797/2017, de 23 de noviembre de $2017^{43}$. Esta sentencia resuelve un recurso de casación interpuesto contra la desestimación de un recurso de apelación por parte del Tribunal Superior de Justicia de Madrid, en relación con un auto autorizando la entrada en una vivienda para llevar a cabo la recuperación de la posesión de un inmueble ocupado ilegalmente y que pretendía, por tanto, el desalojo de sus habitantes. El titular del inmueble era el Instituto de la Vivienda de Madrid (IVIMA).

El interés casacional se manifiesta, afirma el Tribunal Supremo, en la interpretación de los derechos de los menores en el ordenamiento interno e internacional, y en particular en la exigibilidad de que el juez de lo contencioso-administrativo que conoce de la solicitud

\footnotetext{
${ }^{41}$ Sentencia núm. 1263/2018, pp. 28-29.

42 Sentencia núm. 1263/2018, p. 29.

${ }^{43}$ Tribunal Supremo (Sala de lo Contencioso-Administrativo, Sección 3aa), Sentencia núm. 1797/2017, 23 de noviembre de 2017.
} 
de autorización de entrada en un domicilio para su posterior desalojo contemple en su juicio de ponderación la situación particular de los menores afectados, a la luz, entre otros, de la Ley Orgánica de Protección Jurídica del Menor y la Convención sobre los Derechos del Niño ${ }^{44}$. La sentencia busca, por tanto, delimitar el alcance interpretativo de estas normas en relación con la autorización judicial, de cara a determinar si resulta exigible que el juez de lo contencioso-administrativo realice un juicio de proporcionalidad que tenga en cuenta la situación de los menores afectados.

Recuerda el Tribunal Supremo en su sentencia la doctrina consolidada del Tribunal Constitucional que confirma que la resolución judicial por la que se autoriza la entrada en un domicilio debe estar debidamente motivada, cumpliendo la función de garantía de la inviolabilidad del domicilio que le corresponde, "tras efectuar una ponderación de los distintos derechos e intereses que pueden verse afectados y adoptando las cautelas precisas para que la limitación del derecho fundamental que la misma implica se efectúe del modo menos restrictivo posible", de modo que la entrada en el domicilio debe ser absolutamente indispensable para la ejecución del acto administrativo ${ }^{45}$.

La sentencia recurrida en casación, aun teniendo en cuenta esta jurisprudencia constitucional, había considerado que "los derechos de los menores y el derecho a una vivienda digna, son ajenos a la entrada autorizada pues la ocupación de la vivienda ha de ser ostentada y accionada por las vías legalmente previstas y no al margen de las mismas"46. Asimismo, frente a la propuesta de la demandada de retrasar la autorización de entrada en su domicilio hasta que mejorara su situación económica o hasta la finalización del curso escolar, afirmó el Tribunal Superior de Justicia de Madrid que "las cuestiones planteadas de tipo social deberán ser resueltas en su caso por los órganos administrativos municipales o autonómicos a los que correspondan las cuestiones suscitadas pero no en el presente procedimiento de autorización de entrada" ${ }^{\text {. }}$.

El Tribunal Supremo evoca la jurisprudencia del Tribunal Europeo de Derechos Humanos, en particular en los casos Yordanova y Winterstein, para censurar estas afirmaciones. El Tribunal Europeo de Derechos Humanos confirmó en estos casos que toda persona en riesgo de sufrir la pérdida del hogar familiar debe tener una garantía de que la medida ordenando el desalojo sea proporcionada y razonable, y de que esa proporcionalidad y razonabilidad serán valoradas por un tribunal atendiendo a los factores concurrentes de carácter social y personal ${ }^{48}$.

\footnotetext{
${ }^{44}$ Véanse Ley Orgánica 1/1996, de 15 de enero, de Protección Jurídica del Menor, de modificación parcial del Código Civil y de la Ley de Enjuiciamiento Civil, Boletín Oficial del Estado, 17 de enero de 1996, núm. 15, p. 1225; Asamblea General, Convención sobre los Derechos del Niño, A/RES/44/25 (20 de noviembre de 1989).

${ }^{45}$ Tribunal Constitucional (Sala 2a $2^{\mathrm{a}}$ ), Sentencia núm. 188/2013, 4 de noviembre de 2013, FJ 2.

${ }^{46}$ Tribunal Supremo (Sala de lo Contencioso-Administrativo, Sección 3a), Sentencia núm. 1797/2017, p. 8.

${ }^{47}$ Sentencia núm. 1797/2017, p. 9.

${ }^{48}$ Tribunal Europeo de Derechos Humanos (Sección 4a), Yordanova and Others v. Bulgaria, núm. 25446/06, 24 de abril de 2012; Tribunal Europeo de Derechos Humanos (Sección 5a), Winterstein et autres c. France, núm. 27013/07, 17 de octubre de 2013.
} 
El Tribunal Supremo concluye que, en este caso, existió una vulneración de las garantías procesales en el auto autorizando la entrada en el domicilio, "al sostener, sin efectuar un previo juicio de las circunstancias concurrentes [...] que la presencia de menores de edad en la vivienda cuyo desalojo se pretende [...] es 'una cuestión de tipo social', ajena al procedimiento judicial de autorización, 'que debe resolverse por los órganos administrativos municipales o autonómicos" ${ }^{\prime 49}$. Afirma el TS que era insoslayable la consideración de los derechos e intereses de los menores afectados y que la resolución judicial autorizando la entrada en el domicilio contiene una fundamentación inadecuada por insuficiente al no efectuar un juicio sobre la proporcionalidad de la medida adoptada, que incide en la esfera de protección de los derechos e intereses legítimos de los menores. Ordena, por ello, la retroacción de las actuaciones.

A través del ángulo de los derechos de los menores y la Convención sobre los Derechos del Niño, esta jurisprudencia se alinea, por tanto, con los requisitos mencionados repetidamente por el Comité DESC en materia de desalojos forzosos; esto es, la necesidad de un juicio de proporcionalidad que permita al juez examinar las circunstancias concurrentes en cada caso y el riesgo de vulneración del derecho a la vivienda u otros derechos humanos. Si bien la sentencia de Tribunal Supremo en este caso se limita a la autorización de entrada en el domicilio emitida por los jueces del orden contenciosoadministrativo, se abre la posibilidad de extender estas garantías de manera sustantiva al orden civil — puesto que, en cualquier caso, no puede existir desalojo sin intervención judicial que lo avale - y, en mayor medida si cabe, al orden penal, dadas las especiales garantías que rodean los procesos penales.

En este sentido, cabe citar una reciente sentencia de la Audiencia Provincial de Madrid en un recurso de apelación contra una sentencia condenando a los acusados por un delito de usurpación ${ }^{50}$. Esta sentencia aplica la doctrina del estado de necesidad, considerando que la situación económica y familiar de los acusados justificó la ocupación de una vivienda que perteneció en su momento a una entidad bancaria y en la actualidad a una empresa especializada en la compraventa de activos inmobiliarios, que probablemente conocían la ocupación en el momento de adquirir la vivienda. Apunta la sentencia que "si ponemos, como decimos, en una balanza dichos bienes jurídicos, sin duda el bien jurídico de la protección a los menores, a las personas con discapacidad y a la familia prevalece sobre el bien jurídico del derecho a la posesión" ${ }^{\text {. }}$. Estima, por tanto, la concurrencia del estado de necesidad y aplica una eximente completa, conforme al Código Penal.

En conclusión, la jurisprudencia del Tribunal Supremo en las dos sentencias referidas deja entrever una posible línea jurisprudencial receptiva a los pronunciamientos del

\footnotetext{
49 Tribunal Supremo (Sala de lo Contencioso-Administrativo, Sección 3ª), Sentencia núm. 1797/2017, p. 14.

${ }^{50}$ Audiencia Provincial de Madrid (Sección 16 ), Sentencia núm. 613/2018, 11 de septiembre de 2018.

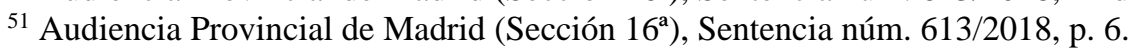


Comité DESC relativos al derecho a la vivienda. Por un lado, se afirma el carácter vinculante de estos pronunciamientos y de las recomendaciones contenidas en ellos en Derecho interno. Sin embargo, cabe preguntarse sobre la distinción entre aquellas recomendaciones que de manera directa se refieren a los autores, requiriendo una reparación o indemnización pecuniaria, y aquellas de alcance general que instan al Estado a tomar medidas para evitar posibles vulneraciones de derechos humanos. Por otro lado, se confirma la obligatoriedad de realizar un juicio de proporcionalidad en ciertos casos antes de autorizar la entrada en un domicilio para ejecutar un desalojo. A pesar de esto, existen dudas sobre la extensión de esta garantía a los órdenes civil y penal. Sería deseable que futura jurisprudencia clarifique estos puntos, refiriéndose de manera explícita a los pronunciamientos del Comité DESC.

\section{Novedades legislativas estatales}

Tras considerar las novedades jurisprudenciales, pasamos ahora a evaluar las novedades legislativas estatales relativas al derecho a la vivienda. Destaca, en primer lugar, la Ley $5 / 2018$, conocida popularmente como ley del "desahucio exprés" (4.1). En segundo lugar, consideramos brevemente el reciente Real Decreto-ley 7/2019, de medidas urgentes en materia de vivienda y alquiler (4.2).

Antes de referirnos a estas normas estatales, cabe mencionar que existe una abundante normativa autonómica sobre derecho a la vivienda y protegiendo su función social ${ }^{52}$. Aunque cada ley autonómica incorpora una regulación ligeramente distinta de la cuestión habitacional, la mayoría de ellas incluyen el deber de dar un uso habitacional efectivo a la vivienda y prevén una definición autónoma del concepto de "vivienda vacía". Incluyen también instrumentos públicos de intervención administrativa en viviendas que no cumplen su función social, tales como el derecho de adquisición preferente, el desahucio administrativo, la expropiación, la venta o sustitución forzosas, las órdenes de ejecución, el alquiler forzoso, las multas coercitivas y las sanciones. Prevén también en su mayor parte una acción pública en materia de vivienda, así como la elaboración de registros

\footnotetext{
52 Véanse, particularmente, Ley 4/2013, de 1 de octubre, de medidas para asegurar el cumplimiento de la función social de la vivienda, Boletín Oficial del Estado, 2 de noviembre de 2013, núm. 263, p. 88451 (Andalucía); Ley 2/2014, de 20 de junio, de modificación de la Ley 2/2003, de 30 de enero, de Vivienda de Canarias y de medidas para garantizar el derecho a la vivienda, Boletín Oficial del Estado, 11 de julio de 2014, núm. 168, p. 54332 (Canarias); Ley 4/2016, de 23 de diciembre, de medidas de protección del derecho a la vivienda de las personas en riesgo de exclusión residencial, Boletín Oficial del Estado, 18 de enero de 2017, núm. 15, p. 4110 (Cataluña); Ley 2/2017, de 3 de febrero, por la función social de la vivienda de la Comunitat Valenciana, Boletín Oficial del Estado, 7 de marzo de 2017, núm. 56, p. 16711 (Comunidad Valenciana); Ley 7/2016, de 21 de julio, de medidas extraordinarias contra la exclusión social, Boletín Oficial del Estado, 10 de agosto de 2016, núm. 192, p. 57357 (Extremadura); Ley 10/2016, de 7 de junio, de Reforma de la Ley 6/2015, de 24 de marzo, de la Vivienda de la Región de Murcia, y de la Ley 4/1996, de 14 de junio, del Estatuto de los Consumidores y Usuarios de la Región de Murcia, Boletín Oficial del Estado, 12 de julio de 2016, núm. 167, p. 48500 (Murcia); Ley Foral 24/2013, de 2 de julio, de medidas urgentes para garantizar el derecho a la vivienda en Navarra, Boletín Oficial del Estado, 27 de julio de 2013, núm. 179, p. 55108 (Navarra); Ley 3/2015, de 18 de junio, de vivienda, Boletín Oficial del Estado, 13 de julio de 2015, núm. 166, p. 57907 (País Vasco).
} 
administrativos de viviendas vacías. El Tribunal Constitucional ha avalado la constitucionalidad de la mayor parte de estos elementos ${ }^{53}$.

\subsection{La Ley 5/2018, del "desahucio exprés"}

La Ley 5/2018, de 11 de junio, se aleja de las garantías que rodean al derecho a la vivienda en Derecho internacional de los derechos humanos, contrastando con los pronunciamientos del Comité DESC y las respuestas jurisprudenciales citadas ${ }^{54}$. Ya en el preámbulo de esta ley se afirma que "la ocupación ilegal, esto es, la ocupación no consentida ni tolerada, no es título de acceso a la posesión de una vivienda ni encuentra amparo alguno en el derecho constitucional a disfrutar de una vivienda digna" ${ }^{55}$. Como hemos mencionado anteriormente, a la luz del Derecho internacional y europeo notablemente las Observaciones Generales núms. 4 y 7 del Comité DESC - el derecho a la vivienda sí ampara los supuestos de ocupación ilegal, que reciben también una protección jurídica independientemente del título por el que se ocupe una determinada vivienda ${ }^{56}$.

La Ley 5/2018 modifica la Ley de Enjuiciamiento Civil, alterando ciertos elementos del procedimiento de tutela sumaria de la tenencia o de la posesión para el caso de vivienda. Permite así que soliciten la inmediata recuperación de la posesión de una vivienda o parte de ella "la persona física que sea propietaria o poseedora legítima por otro título, las entidades sin ánimo de lucro con derecho a poseerla y las entidades públicas propietarias o poseedoras legítimas de vivienda social"57. Quedan excluidas, por tanto, las personas jurídicas con ánimo de lucro, como entidades financieras o fondos de inversión, que no podrán acudir a este mecanismo especial en ningún caso.

Una vez ejercitada la acción de recuperación de la posesión de una vivienda, se requerirá a sus ocupantes para que aporten en el plazo de cinco días el título justificando su situación posesoria. Si esto no ocurre, el tribunal ordenará mediante auto la inmediata

\footnotetext{
${ }^{53}$ En términos generales, el Tribunal Constitucional ha ratificado la constitucionalidad de las provisiones que regulan el uso habitacional y la función social de la vivienda, así como la mayoría de los instrumentos públicos de intervención administrativa, salvo la expropiación temporal de uso de viviendas incursas en procedimientos de desahucio y la acción pública judicial en materia de vivienda. Véanse, entre otras, Tribunal Constitucional (Pleno), Sentencia núm. 97/2018, 19 de septiembre de 2018; Tribunal Constitucional (Pleno), Sentencia núm. 43/2018, 26 de abril de 2018; Tribunal Constitucional (Pleno), Sentencia núm. 80/2018, 5 de julio de 2018; Tribunal Constitucional (Pleno), Sentencia núm. 16/2018, 22 de febrero de 2018.

${ }^{54}$ Ley 5/2018, de 11 de junio, de modificación de la Ley 1/2000, de 7 de enero, de Enjuiciamiento Civil, en relación a la ocupación ilegal de viviendas, Boletín Oficial del Estado, 12 de junio de 2018, núm. 142, p. 60209.

${ }^{55}$ Ley 5/2018, de 11 de junio, de modificación de la Ley 1/2000, de 7 de enero, de Enjuiciamiento Civil, en relación a la ocupación ilegal de viviendas, preámbulo.

${ }^{56}$ Véanse Comité de Derechos Económicos, Sociales y Culturales, Observación general núm. 4: El derecho a una vivienda adecuada (párrafo 1 del artículo 11 del Pacto); Comité de Derechos Económicos, Sociales y Culturales, Observación general núm. 7: El derecho a una vivienda adecuada (párrafo 1 del artículo 11 del Pacto): los desalojos forzosos.

${ }^{57}$ Ley 5/2018, de 11 de junio, de modificación de la Ley 1/2000, de 7 de enero, de Enjuiciamiento Civil, en relación a la ocupación ilegal de viviendas, artículo único, párrafo dos.
} 
entrega de la posesión de la vivienda al demandante. Contra este auto no cabe recurso alguno. La oposición del demandado podrá fundarse exclusivamente en la existencia de título suficiente para poseer o en la falta de título por parte del actor. Si el demandado o demandados no contestan a la demanda en plazo, se procede de inmediato a dictar sentencia estimatoria, que será inmediatamente ejecutable ${ }^{58}$. El legislador desconoce así las reiteradas resoluciones del Comité DESC subrayando la necesidad de que se examinen las circunstancias de cada caso particular antes de proceder a un desalojo y de prever recursos judiciales efectivos que permitan revisar la proporcionalidad de esta medida.

La Sentencia del Tribunal Constitucional núm. 32/2019, de 28 de febrero de 2019, ratificó la constitucionalidad de esta ley, considerando que no vulnera los derechos a la tutela judicial efectiva, a la inviolabilidad del domicilio ni a una vivienda digna ${ }^{59}$. En cuanto al derecho a una vivienda digna y adecuada, el Tribunal Constitucional parece afirmar que, puesto que el artículo 47 de la Constitución no garantiza un derecho fundamental sino un principio rector de la política social y económica, este no puede utilizarse directamente para evaluar la constitucionalidad de las leyes. Niega, además, que estos tratados internacionales de derechos humanos puedan servir directamente para controlar la constitucionalidad de normas o actos en Derecho interno que pudieran vulnerar derechos fundamentales.

El Tribunal afirma así que:

"De todos modos, ni siquiera en la hipótesis de que el art. $47 \mathrm{CE}$ reconociese un derecho fundamental - lo que no es el caso - cabría admitir que los textos internacionales sobre derechos humanos invocados por los recurrentes constituyesen canon para el control de constitucionalidad de la regulación legal impugnada. Este Tribunal tiene reiteradamente declarado, y procede recordarlo una vez más, que la utilidad hermenéutica de los tratados y acuerdos internacionales sobre derechos humanos ratificados por España para configurar el sentido y alcance de los derechos fundamentales, de conformidad con lo establecido en el art. 10.2 CE, no convierte a tales instrumentos internacionales en canon autónomo de validez de las normas y actos de los poderes públicos desde la perspectiva de los derechos fundamentales. De suerte que una eventual contradicción por una ley de esos tratados no puede fundamentar la pretensión de inconstitucionalidad de esa ley por oposición a un derecho fundamental" ${ }^{\prime 60}$.

De esta distinción rígida y formalista dentro del control de constitucionalidad se desmarca la magistrada Balaguer Callejón en su voto particular concurrente, en el que expone que no existe, a su juicio, una exclusión explícita referida a los principios rectores en relación

\footnotetext{
${ }^{58}$ Véase Ley 1/2000, de 7 de enero, de Enjuiciamiento Civil, arts. 441.1 bis y 444.1 bis.

${ }^{59}$ Tribunal Constitucional (Pleno), Sentencia núm. 32/2019, de 28 de febrero de 2019.

${ }^{60}$ Tribunal Constitucional (Pleno), Sentencia núm. 32/2019, FJ 6.
} 
con el mandato del artículo 10.2 de la Constitución, señalando otros supuestos en los que el Tribunal Constitucional sí ha acudido a fuentes internacionales para delimitar el alcance de derechos constitucionales ${ }^{61}$.

Así, la interpretación mayoritaria del Tribunal Constitucional encaja difícilmente con la idea de interrelación e interdependencia de los derechos humanos, recogida en múltiples instrumentos internacionales y europeos. Recordemos, además, que España tiene la obligación de garantizar de manera inmediata el contenido esencial del derecho a la vivienda y de tomar todas las medidas posibles a su alcance, "hasta el máximo de sus recursos disponibles", para garantizar progresivamente este derecho.

El Pleno avala, además, el mecanismo especial introducido por la Ley 5/2018, que no prevé un juicio de razonabilidad y proporcionalidad previo a decretar el desalojo ni recoge la posibilidad de que el demandado se oponga a este con base en la posible vulneración de su derecho a la vivienda o de otros derechos humanos. Como hemos visto anteriormente, estas garantías han sido interpretadas por parte del Comité DESC como necesarias para garantizar el derecho a la vivienda y la prohibición de desalojos forzosos sin alternativa habitacional recogidos en el PIDESC.

Por su parte, el Tribunal Europeo de Derechos Humanos ha asegurado en diversas ocasiones que toda persona en riesgo de perder su hogar debe tener la posibilidad de que la proporcionalidad de esa medida se revise por un tribunal independiente ${ }^{62}$. En su reciente sentencia F.J.M. contra el Reino Unido, de noviembre de 2018, el Tribunal Europeo de Derechos Humanos parece haber matizado este requisito para los casos que involucran solo a particulares; en cambio, para el caso de entidades públicas titulares de vivienda social este principio sigue plenamente vigente ${ }^{63}$.

Cabe aclarar que la exigencia de un juicio de razonabilidad y proporcionalidad no implica que, en cada caso, el juez deba realizar una investigación minuciosa de todas y cada una de las circunstancias concurrentes. En ciertos supuestos, como la ocupación de una vivienda familiar habitual aprovechando un período de ausencia, el juicio de proporcionalidad puede ser sumario, pero debería estar en todo caso debidamente justificado y explicitado. En otros supuestos, como la ocupación de una vivienda vacía de titularidad pública a la que la Administración no ha dado uso por largo tiempo, el juicio de proporcionalidad y razonabilidad podría arrojar un resultado distinto.

\footnotetext{
61 Sentencia núm. 32/2019, Voto particular concurrente que formula la magistrada doña María Luisa Balaguer Callejón.

${ }^{62}$ Véase Tribunal Europeo de Derechos Humanos (Sección 4a ), McCann v. the United Kingdom, núm. 19009/04, 13 de mayo de 2008.

${ }^{63}$ Tribunal Europeo de Derechos Humanos (Sección 1 ${ }^{\text {a }}$, F.J.M. v. the United Kingdom, núm. 76202/16, 6 de noviembre de 2018. Véase, para un breve análisis del caso, Benito Sánchez, Juan Carlos, "F.J.M. v. the United Kingdom: Judicial review of the proportionality of an eviction in private rental housing", Strasbourg Observers, 15 de enero de 2019, https://strasbourgobservers.com/2019/01/15/f-j-m-v-the-united-kingdomjudicial-review-of-the-proportionality-of-an-eviction-in-private-rental-housing/.
} 
En cualquier caso, esta evaluación debe ser previa a todo desalojo, sirviendo así como garante del derecho a la vivienda pero también del derecho a la igualdad y no discriminación de los colectivos más vulnerables, a los que pertenecen la mayor parte de quienes ocupan sin título. La Ley 5/2018 supone, en este sentido, un paso contrario a la garantía del derecho a una vivienda adecuada a la luz de la interpretación del Comité DESC y del Derecho internacional y europeo de los derechos humanos.

\title{
4.2. El Real Decreto-ley 7/2019, de medidas urgentes en materia de vivienda $y$ alquiler
}

En marzo de 2019, el Gobierno español adoptó el Real Decreto-ley 7/2019, de medidas urgentes en materia de vivienda y alquiler, que fue convalidado el 4 de abril de 2019 por la Diputación Permanente del Congreso de los Diputados ${ }^{64}$. En este real decreto-ley se introducen una serie de cambios sobre la legislación estatal en materia de vivienda. En el mismo preámbulo se hace ya una referencia a los pronunciamientos del Comité DESC, en los siguientes términos:

\begin{abstract}
"Además, resulta necesario en este punto avanzar en el cumplimiento de nuestros compromisos con los acuerdos internacionales sobre derechos sociales en una materia que no admite demora. En este sentido, cabe recordar el Dictamen del Comité de Derechos Económicos, Sociales y Culturales del Consejo Económico y Social de Naciones Unidas, adoptado el 20 de junio de 2017 en el que, entre otros aspectos, instaba al Gobierno de España a asegurar que su legislación y su aplicación sea conforme con las obligaciones establecidas en el Pacto Internacional de Derechos Económicos, Sociales y Culturales. Y, en particular, señalaba la obligación de adoptar las medidas necesarias para superar los problemas de falta de coordinación entre las decisiones judiciales y las acciones de los servicios sociales en los procedimientos de desahucio de la vivienda habitual cuando afecta a hogares especialmente vulnerables".
\end{abstract}

El real decreto-ley establece una duración más extensa para los contratos de alquiler (cinco años si el propietario es persona física y siete años si es persona jurídica, renovables por tres años en ambos supuestos), establece un límite máximo a las garantías pecuniarias que el propietario puede exigir, determina que la renta sea indexada de acuerdo con la inflación, modifica ciertas normas fiscales, crea un índice de referencia estatal de precios de alquiler (que no es vinculante, sino que sirve solamente un propósito informativo), termina con la práctica de los "desahucios abiertos" o sin fecha y crea un

\footnotetext{
${ }^{64}$ Real Decreto-ley 7/2019, de 1 de marzo, de medidas urgentes en materia de vivienda y alquiler, Boletín Oficial del Estado, 5 de marzo de 2019, núm. 5, p. 21007. 
nuevo procedimiento de coordinación entre tribunales y servicios sociales en casos de desahucio por impago de alquiler.

En particular, se introduce un nuevo procedimiento por el cual el juez debe informar al demandado sobre la posibilidad de contactar con los servicios sociales para que examinen si existe una situación de vulnerabilidad. Al mismo tiempo, los jueces deben, de oficio, comunicar el proceso de desahucio en curso a los servicios sociales competentes. Si estos confirman que el hogar se encuentra en una situación de vulnerabilidad social o económica, deben notificar inmediatamente al tribunal que conoce del asunto. Cuando el juez reciba esta notificación, debe suspender el desalojo hasta que las medidas que se consideren necesarias por los servicios sociales sean adoptadas, por un período máximo de un mes si el demandante es persona física o de tres meses si el demandante es persona jurídica. Cuando aquellas medidas hayan sido adoptadas o este plazo haya terminado, la suspensión se retirará y el proceso de desahucio continuará.

Esto implica que el juez aún no tiene la posibilidad de suspender el desalojo hasta que se disponga de una alternativa habitacional adecuada si esta alternativa no está disponible en uno o tres meses, respectivamente. En la práctica, considerando la falta de vivienda disponible en el seno de las administraciones municipales y autonómicas, esto ocurrirá en gran parte de los casos. El juez tampoco dispone en términos generales de la posibilidad de examinar la razonabilidad y proporcionalidad del desahucio antes de ordenarlo, o de evaluar la posibilidad de que las personas afectadas puedan quedar en situación de sinhogarismo.

El real decreto-ley no contiene ninguna referencia a la obligatoriedad de las solicitudes de medidas provisionales adoptadas por el Comité DESC ni introduce la necesidad de garantizar una consulta genuina y efectiva con los afectados en el marco de este procedimiento, que no es además aplicable a las ocupaciones sin título. La norma incluye un mandato al Ministerio de Fomento para que movilice suelo público para promover vivienda asequible a través de la cooperación público-privada, pero no prevé ningún plan a corto o medio plazo para luchar contra la emergencia habitacional en España.

Por tanto, esta nueva regulación, más allá de mencionar el Comité DESC y el caso Ben Djazia en su preámbulo, no parece haber incorporado verdaderamente las reiteradas recomendaciones del Comité a los efectos de mejorar la garantía del derecho a una vivienda adecuada. Considerando la gran cantidad de casos relativos a desalojos forzosos y derecho a la vivienda pendientes ante el Comité DESC, habrá que observar si esta nueva normativa repercute favorablemente sobre este tipo de situaciones y si futuras resoluciones del Comité DESC obligan a España a dar una respuesta más firme en este sentido.

\section{Conclusión}


Este artículo ha comenzado con un resumen analítico de los pronunciamientos del Comité de Derechos Económicos, Sociales y Culturales (Comité DESC) de Naciones Unidas relativos a España en materia de vivienda entre 2017 y 2018, tanto en el marco del mecanismo de evaluación periódica de los Estados parte en el Pacto Internacional de Derechos Económicos, Sociales y Culturales (PIDESC) como del mecanismo de comunicaciones individuales previsto por el Protocolo Facultativo a dicho Pacto. A su vez, dentro de este mecanismo de comunicaciones individuales, hemos diferenciado entre las solicitudes de medidas provisionales emitidas por el Comité DESC mientras evalúa una comunicación y los dictámenes que adopta una vez concluido su examen. Hemos hecho una especial referencia al caso Ben Djazia et al. y a la problemática de los desalojos forzosos.

Seguidamente, se ha considerado la recepción en el orden interno de estos pronunciamientos, a través de un examen de las novedades jurisprudenciales y legislativas a nivel estatal en este sentido. Ante la ausencia de jurisprudencia abordando estos pronunciamientos de manera explícita, hemos tomado como referencia dos sentencias del Tribunal Supremo que tratan respectivamente sobre el carácter vinculante en Derecho interno de los dictámenes emitidos por órganos de supervisión de tratados y sobre la obligatoriedad de tener en cuenta los derechos del niño en un juicio de proporcionalidad previo a autorizar ciertos desalojos.

En cuanto a la recepción legislativa, dejando de lado la abundante normativa autonómica y centrándonos en las novedades a nivel estatal, hemos evaluado la conocida como ley del "desahucio exprés", que supone un claro desconocimiento de las garantías que rodean al derecho a la vivienda en Derecho internacional y europeo de los derechos humanos. Se ha hecho también una breve referencia al real decreto-ley de medidas urgentes adoptado en abril de 2019, que recoge algunas de las recomendaciones del Comité pero sin incorporar tampoco aquellas garantías jurídicas en su totalidad.

Del análisis expuesto pueden desprenderse una serie de sugerencias de lege ferenda relativas al derecho a la vivienda y a la protección judicial contra los desalojos. En primer lugar, parece imprescindible prever un cauce específico para que los jueces y tribunales competentes adopten de manera directa las medidas provisionales solicitadas por el Comité DESC, sin que exista la posibilidad de obviar estas medidas y de proceder con los lanzamientos. En segundo lugar, es imperativo mejorar la protección judicial de las personas en riesgo de ser desalojadas. A la luz de los pronunciamientos del Comité, debe introducirse la obligación de realizar un juicio de razonabilidad y proporcionalidad con carácter previo a cualquier desalojo, que permita examinar las circunstancias económicas, sociales y familiares de cada caso y que permita evaluar el riesgo de que el desalojo conlleve una vulneración del derecho a la vivienda o de otros derechos humanos. Además, debe reconocerse el acceso a un recurso judicial efectivo y apropiado que permita revisar la proporcionalidad de estas medidas. Ello debe ir acompañado, en su caso, de la 
posibilidad de obtener asistencia jurídica gratuita, sin que esta pueda ser denegada sobre la base de la no sostenibilidad de la pretensión jurídica del demandado. 